\title{
Tolerância à dessecação de sementes de Cinnamomum zeylanicum Ness
}

\section{Dessication tolerance of Cinnamomum zeylanicum Ness Seeds}

\author{
Kelina Bernardo Silva ${ }^{1 *}$; Edna Ursulino Alves²; Riselane de Lucena Alcântara \\ Bruno $^{2}$; Sueli da Silva Santos ${ }^{3}$; Leandra Matos Barroso ${ }^{4}$
}

\section{Resumo}

Com o objetivo de avaliar a qualidade fisiológica das sementes de canela (Cinnamomum zeylanicum Ness) submetidas a diferentes níveis de secagem, os frutos de coloração marrom escura e completamente maduros foram coletados e despolpados manualmente, em seguida, as sementes foram expostas para a secagem, sobre papel toalha, em condições de laboratório. Os tratamentos consistiram na amostragem para a determinação do teor de água, testes de germinação e vigor no início do experimento e após 12 , $24,36,48,60,72,84$ e 96 horas. O delineamento experimental utilizado foi o inteiramente ao acaso, em quatro repetições de 25 sementes cada. Os dados obtidos foram submetidos à análise de variância e de regressão polinomial. As sementes de canela são dispersas com alto teor de água $(39,43 \%)$ e tem a viabilidade comprometida quando desidratadas; a capacidade de germinação bem como a sua velocidade diminui com a desidratação, caracterizando o comportamento recalcitrante das sementes; com teor de água inferior a $34,82 \%$ tanto a porcentagem quanto a velocidade de germinação são reduzidas. As sementes de C. zeylanicum toleram a dessecação até 12 horas sem perdas significativas da qualidade fisiológica.

Palavras-chave: Cinnamomum zeylanicum, sementes recalcitrantes, germinação, vigor

\begin{abstract}
In order to evaluate the physiological quality of seeds of Cinnamomum zeylanicum Ness, submitted to different levels of drying, the fruits of dark brown and fully mature were collected and washed by hand, then the seeds were exposed to drying, on paper towel, under laboratory conditions. Treatments consisted of sampling for the determination of water content, germination and vigor tests at the beginning of the experiment and after 12, 24, 36, 48, 60, 72, 84 and 96 hours. The experimental design was completely randomized with four replications of 25 seeds each. The data were subjected to analysis of variance and polynomial regression. Cinnamon seeds are dispersed with high water content $(39.43 \%)$ and viability is compromised when dehydrated, the germination capacity as well as its speed decreases with dehydration, characterizing the recalcitrant behavior of seeds, with water content $34.82 \%$ less than both the percentage and the speed of germination are reduced. The seeds of C. zeylanicum tolerate desiccation to 12 hours without significant loss of vigor.
\end{abstract}

Key words: Cinnamomum zeylanicum, recalcitrant seeds, germination, vigor

\footnotetext{
1 Agrônoma, Dr ${ }^{\mathrm{a}}$ em Agronomia, Dept ${ }^{\mathrm{o}}$. de Fitotecnia, CCA, Universidade Federal da Paraíba, UFPB, Areia, PB. E-mail: kelinabernardo@yahoo.com.br

2 Prof $^{a}$. Adjunta do Dept ${ }^{\circ}$. de Fitotecnia, CCA, UFPB, Areia, PB. E-mail: ednaursulino@cca.ufpb.br

3 Eng $^{\mathrm{a}} \mathrm{Agr}^{\mathrm{a}}$, Dept ${ }^{\mathrm{O}}$. de Fitotecnia, CCA, UFPB, Areia, PB. E-mail: suelidasilvasantos@yahoo.com.br

4 Mestre em Agronomia Dept ${ }^{\circ}$. de Fitotecnia, CCA, UFPB, Areia, PB. E-mail: leandrabarrozo@yahoo.com.br

* Autor para correspondência 


\section{Introdução}

A canela (Cinnamomum zeylanicum Ness) é uma árvore originária do Ceilão, da Birmânia e da Índia, pertencente à família das Lauráceas. A espécie possui outros nomes populares, como: caneleira, caneleira-da-índia, caneleira-de-ceilão, cinamomo e pau-canela. A caneleira é uma árvore que requer cerca de $1.300 \mathrm{~mm}$ de chuva por ano e temperatura média anual superior a $21{ }^{\circ} \mathrm{C}$. A casca dos ramos é comercializada em rama (pau), raspas e pó. $C$. zeylanicum é utilizada na culinária e na fabricação de bebidas, medicamentos, perfumes e sabonetes. A canela é uma árvore de ciclo perene e que atinge até 8 a $9 \mathrm{~m}$ de altura. $\mathrm{O}$ tronco alcança cerca de $35 \mathrm{~cm}$ de diâmetro. As folhas são coriáceas, lanceoladas, com nervuras na base, brilhantes e lisas na parte superior e verde-claras e finamente reticuladas na parte inferior. As flores são de coloração amarela ou esverdeada, numerosas e bem pequenas, agrupadas em cachos ramificados. É muito utilizada na medicina popular por apresentar propriedades medicinais, tais como: adstringente, afrodisíaca, anti-séptica, aperiente, aromática, carminativa, digestiva, estimulante, hipertensora, sedativa, tônica e vaso dilatadora (JARDIM DE FLORES, 2009).

O comportamento ortodoxo ou recalcitrante em sementes, segundo Barbedo e Bilia (1998), pode ser originado de mecanismos de escape de destruição celular durante a perda de água. Quando células não tolerantes à dessecação são desidratadas, algumas consequências são observadas: seus solutos podem ficar mais concentrados, aumentando as reações químicas destrutivas; alguns solutos podem cristalizar, modificando a resistência iônica e o pH da solução intracelular; iniciando-se a desnaturação das proteínas e a ruptura das membranas celulares.

Sementes recalcitrantes não suportam, teores de água abaixo de níveis relativamente altos (40 a 50\%) sem perda de viabilidade (ROBERTS, 1973). Porém, há sementes que perdem a capacidade de germinar na reidratação, pois moléculas de água absorvidas podem não se ligar aos sítios corretos e podem não ocorrer os necessários reparos das membranas celulares que evitam a excessiva perda de solutos, comprometendo o processo germinativo (SALOMÃO; FUJICHIMA, 2002).

As sementes recalcitrantes têm a característica de germinar antes ou imediatamente após a separação da planta-mãe, principalmente porque continuam hidratadas até o final da maturação. Embora a viabilidade seja reduzida quando as sementes são armazenadas com elevado teor de água, para sementes recalcitrantes alguns pesquisadores têm mantido o teor de água elevado por meio do acondicionamento em embalagens herméticas, sob baixas temperaturas e, desta forma, têm conseguido ampliar sua longevidade natural (BARBEDO; MARCOS FILHO, 1998).

Nas sementes recalcitrantes, de forma geral, em nenhum momento do desenvolvimento se verifica tolerância à dessecação, motivo pelo qual estas sementes apresentam grande dificuldade em sua conservação (BARBEDO; MARCOS FILHO, 1998; HARTMANN et al., 1997). Para isso, tornase necessário o controle de alterações que ocorrem durante o armazenamento e a eventual necessidade ou sensibilidade das sementes ao processo de dessecação (KERMODE, 1990, CARVALHO; NAKAGAWA, 2000), sendo importante quantificar o processo (WALTERS, 2000).

A perda de água estrutural durante o processo de secagem pode causar alteração de sistemas metabólicos e de membranas, resultando no início do processo de deterioração (FARRANT; PAMMENTER; BERJAK, 1988). Já a viabilidade dessas sementes é reduzida quando o teor de água atinge valores inferiores àqueles considerados críticos; quando iguais ou inferiores àqueles considerados letais, há perda total da viabilidade (HONG; ELLIS, 1992). A sensibilidade das sementes recalcitrantes à dessecação depende da espécie, sendo os teores crítico e letal de água relativamente altos, respectivamente, de 27 a $38 \% \mathrm{e}$ de 12 a $22 \%$ para sementes de Euterpe edulis Mart. (ANDRADE; PEREIRA, 1997). 
O presente trabalho foi desenvolvido com o objetivo de avaliar a qualidade fisiológica das sementes das sementes de C. zeylanicum submetidas a diferentes níveis de secagem.

\section{Material e Métodos}

O presente trabalho foi conduzido no Laboratório de Análise de Sementes (LAS) do Departamento de Fitotecnia e Ciências Ambientais da Universidade Federal da Paraíba-PB.

Os frutos de C. zeylanicum, de coloração marrom escura e completamente maduros foram colhidos em árvores matrizes localizados no município Areia$\mathrm{PB}$, a 574,62 $\mathrm{m}$ de altitude, latitude $6^{\circ} 58^{\prime} 12^{\prime}$ ' $\mathrm{S}$ e longitude $35^{\circ} 42^{\prime} 15^{\prime}$ ' W. Posteriormente, os frutos foram transportados em embalagem de polietileno até o laboratório (LAS), e despolpados manualmente para a retirada do epicarpo e mesocarpo.

Após o processamento dos frutos, a umidade das sementes foi determinada, antes e após cada período de secagem utilizando-se quatro sub-amostras de 10 sementes para cada tratamento, pelo método da estufa a $105 \pm 3{ }^{\circ} \mathrm{C}$ por 24 horas, seguindo as recomendações de Brasil (2009), à exceção do tamanho da amostra e número de repetições.

As sementes foram colocadas para secar, em camada uniforme e única sobre papel toalha em bandejas plásticas e condicionadas em sala com janelas e ventilação ambiente. Os tratamentos com diferentes grau de umidade foram obtidos pela secagem das sementes nesse ambiente por períodos variáveis. Foram retiradas amostras para a determinação do teor de água e para os testes de emergência e germinação, no início do experimento e após 12, 24, 36, 48, 60, 72, 84 e 96 horas de secagem.

O teste de emergência de plântulas foi realizado em ambiente protegido, com quatro repetições de 25 sementes, semeadas em bandejas plásticas com dimensões de 41 x 36 × 7,6 cm de comprimento, largura e profundidade, respectivamente, contendo areia lavada e esterilizada, cuja manutenção da umidade foi por meio de irrigações diárias. A contagem do número de plântulas emergidas foi realizada quando os cotilédones se encontravam acima do solo, sendo os resultados expressos em percentagem.

O teste de germinação foi conduzido em papel germitest, umedecido com quantidade equivalente a 2,5 vezes de água destilada em relação ao peso do papel, e as sementes foram distribuídas sobre uma dupla folha de papel e cobertas por uma única, em quatro repetições de 25 sementes. Posteriormente foram feitos rolos e colocados em sacos plásticos, que foram colocados em germinador tipo BOD à temperatura de $25^{\circ} \mathrm{C}$ sob 8 horas luz e 16 horas de escuro. A contagem das plântulas foi realizada no décimo dia após a instalação do experimento, cujo critério utilizado nas avaliações foi o de plântulas normais, ou seja, quando haviam emitido a raiz e o epicótilo.

O Índice de velocidade de emergência (IVE) e de germinação (IVG) foram determinados juntamente com o teste de emergência e de germinação, com contagens realizadas a cada 2 dias, por um período de 30 dias após a instalação dos testes. O índice foi calculado utilizando-se a fórmula proposta por Maguire (1962). Para o comprimento e massa seca de plântulas, ao final do teste de emergência e de germinação, as plântulas normais avaliadas anteriormente foram medidas com o auxílio de uma régua graduada, sendo os resultados expressos em centímetros por plântula. Logo após as medições, as plântulas normais tiveram seus cotilédones removidos, e essas foram mantidas em sacos de papel e levadas a estufa regulada a $65^{\circ} \mathrm{C}$ até atingir massa constante. Decorrido este período, as mesmas foram pesadas em balança analítica com precisão de $0,001 \mathrm{~g}$.

O delineamento experimental utilizado foi o inteiramente ao acaso, em quatro repetições de 25 sementes cada. Os dados obtidos foram submetidos à análise de variância e de regressão polinomial, 
verificando-se os efeitos linear, quadrático e cúbico das variáveis, em função dos tratamentos, sendo selecionado para expressar o comportamento de cada variável, o modelo significativo de maior ordem.

\section{Resultados e Discussão}

O teor de água inicial das sementes de $C$. zeylanicum após a coleta e despolpamento foi de 39,43\%. A secagem por um período de até 96 horas ocasionou redução gradual no teor de água, conforme se observa na Figura 1.

Figura 1. Grau de umidade (\%) das sementes de $C$. zeylanicum em função de diferentes períodos de secagem em condições de laboratório.

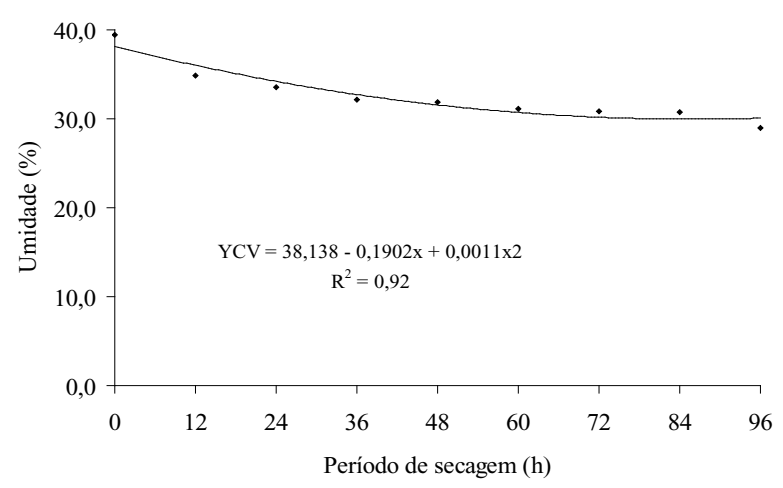

Fonte: Elaboração dos autores.

A redução no teor de água das sementes foi mais intensa nos períodos iniciais de secagem, especialmente nas primeiras 12 horas, diminuindo gradativamente o percentual de redução com o aumento do período de secagem.

A germinação apresentou valores decrescentes até 96 horas de secagem, evidenciando a sua dependência ao teor de água das sementes (Figura 2). Comportamento semelhante foi apresentado pelo IVE e IVG (Figura 3). Em sementes de Myrciaria dúbia (camu-camu) a redução do teor de água, de $46 \%$ para $40 \%$ afetou negativamente a viabilidade e o vigor das sementes armazenadas (FERREIRA; GENTIL, 2003).
A exposição das sementes à dessecação, nas condições em que foi executado o experimento comprova que essas têm um período de tolerância à dessecação de 12 horas, quando foi atingido o teor de água de $34,82 \%$. A partir desse período a porcentagem e a velocidade de germinação foram afetadas significativamente. Esse teor de água pode ser considerado o nível crítico mencionado por Barbedo e Marcos Filho (1998), que relataram como aquele abaixo do qual a semente recalcitrante não suporta a secagem. Este teor de água crítico seria atingido após a perda de toda a água celular livre, e em diversos trabalhos e espécies pesquisadas foram obtidos valores de 15 a $38 \%$, demonstrando que esta característica é variável de acordo com a espécie e com o indivíduo.

Figura 2. Emergência de plântulas e germinação de sementes de C. zeylanicum em função de diferentes períodos de secagem em condições de laboratório.
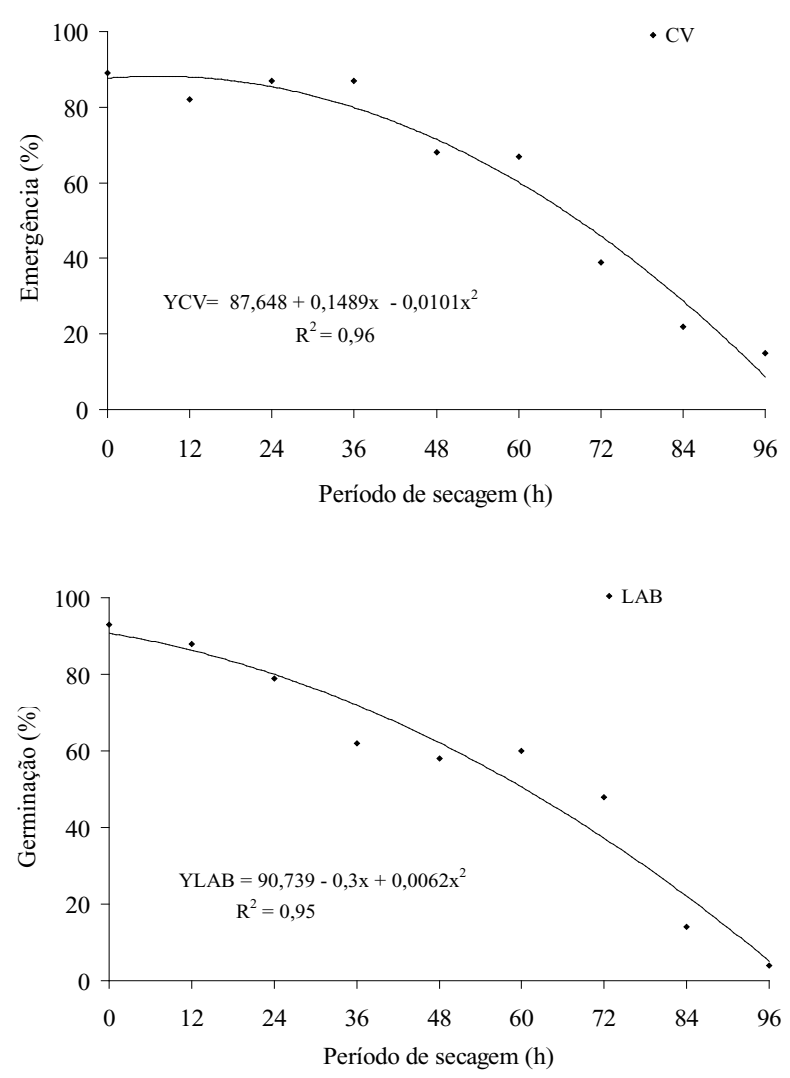

Fonte: Elaboração dos autores. 
Figura 3. Índice de velocidade de emergência de plântulas (IVE) e de germinação (IVG) de sementes de C. zeylanicum em função de diferentes períodos de secagem em condições de laboratório.
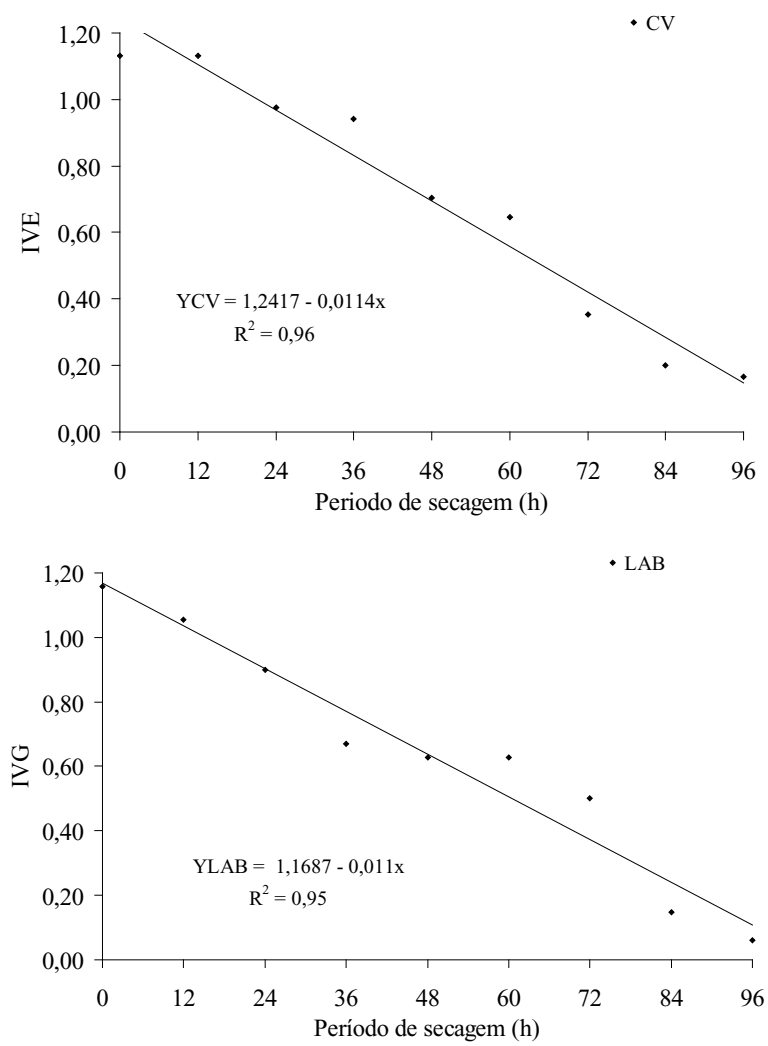

Fonte: Elaboração dos autores.

De acordo com os resultados a desidratação crescente intensificou o processo de deterioração das sementes (Figuras 2 e 3), como pode ser verificado pela velocidade e porcentagem de germinação. Isso caracteriza o comportamento recalcitrante das sementes de canela (Cinnamomum zeylanicu Ness).

Trabalhando com sementes de Euterpe espiritosantensis, Martins, Nakagawa e Bovi (1999) obtiveram percentagem alta de germinação $(90,0 \%$ a $87,5 \%)$ quando as sementes não sofreram desidratação (teor inicial de água de 51,4\% a 46,6\%). Abaixo de uma faixa de teor de água situada entre $40,7 \%$ e $51,4 \%$, os valores de germinação e vigor foram significativamente reduzidos e a mortalidade total das sementes foi observada, com a redução do teor de água das sementes a uma faixa situada entre $13,4 \%$ e $15,8 \%$.
A partir das 12 horas de secagem, observa-se que o comprimento (Figura 4) e a massa seca das plântulas de canela (Figura 5), foram sendo afetadas gradualmente.

Figura 4. Comprimento de plântulas $(\mathrm{cm})$ de $C$. zeylanicum em função de diferentes períodos de secagem em condições de laboratório.
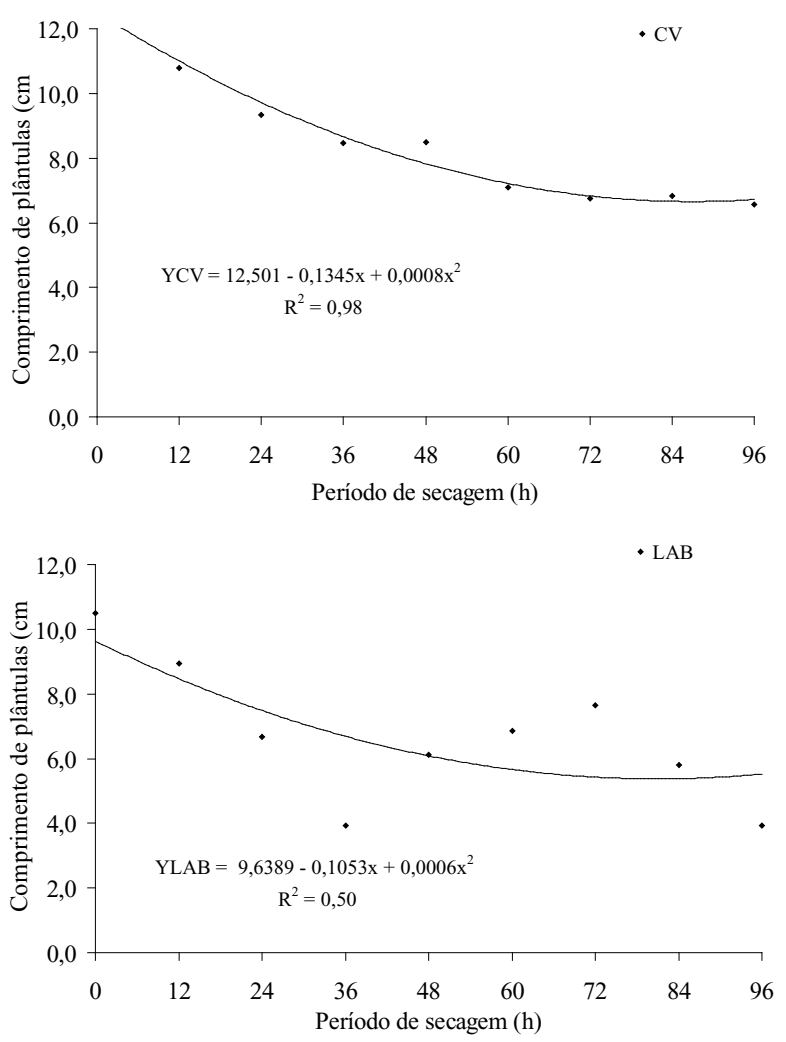

Fonte: Elaboração dos autores.

A desidratação crescente afetou o vigor, com o aumento do tempo emergência, redução da velocidade de germinação e emergência, bem como, o comprimento e a massa seca de plântulas de canela. Nascimento, Novembre e Cicero (2007), avaliando as consequências fisiológicas da dessecação em sementes de açaí (Euterpe oleracea Mart.), também constataram reduções da velocidade de emergência aumento do tempo médio de germinação, redução da velocidade de emergência, do comprimento e da massa seca de plântulas. 
Figura 5. Massa seca de plântulas (g) de C. zeylanicum em função de diferentes períodos de secagem em condições de laboratório.
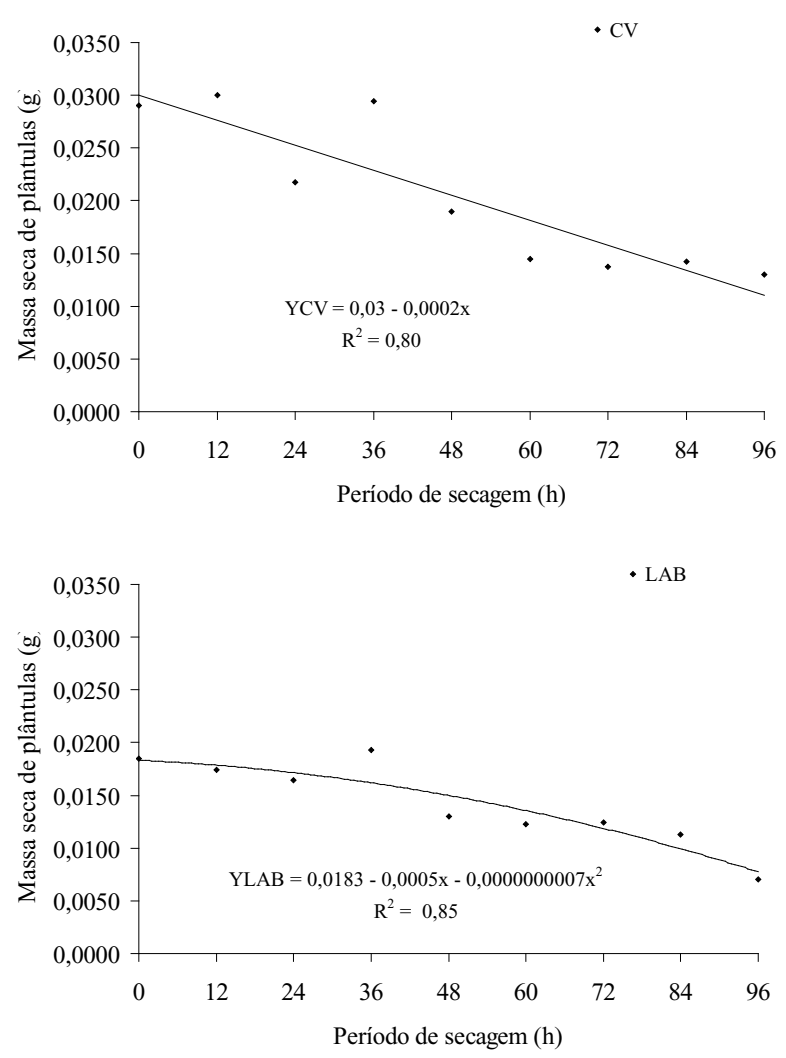

Fonte: Elaboração dos autores.

\section{Conclusões}

Com teor de água inferior a 34,82\% tanto a porcentagem quanto a velocidade de germinação das sementes de $C$. zeylanicum são reduzidas significativamente;

As sementes de $C$. zeylanicum toleram a dessecação até 12 horas, quando atingem um teor de água de 34,82\%, em condições de laboratório, sem perdas significativas da qualidade fisiológica.

\section{Referências}

ANDRADE, A. C. S.; PEREIRA, T. S. Comportamento de armazenamento de sementes de palmiteiro (Euterpe edulis Mart.). Pesquisa Agropecuária Brasileira, Brasília, v. 32, n. 10, p. 987-991, 1997.
BARBEDO, C. J.; MARCOS FILHO, J. Tolerância à dessecação em sementes. Acta Botânica Brasilica, São Paulo, v. 12, n. 2, p. 145-164, 1998.

BARBEDO, C. J.; BILIA, D. A. C. Evolution of research on recalcitrant seeds. Scientia Agrícola, Piracicaba, v. 55, p. 121-125,1998. Especial.

BRASIL, Ministério da Agricultura e da Reforma Agrária. Regras para análise de sementes. Secretaria de Defesa Agropecuária. Brasília: MAPA/ACS, 2009, 399 p.

CARVAlHO, N. M.; NAKAGAWA, J. Sementes: ciência, tecnologia e produção. 4. ed. Funep: Jaboticabal, 2000.

FARRANT, J. M.; PAMMENTER, N. W.; BERJAK, P. Recalcitrance - a current assessment. Seed Science and Technology, Zurich, v. 16, n. 1, p. 155-166, 1988.

FERREIRA, S. A. N.; GENTIL, D. F. O. Armazenamento de sementes de camu-camu (Myrciaria dubia) com diferentes graus de umidade e temperaturas. Revista Brasileira de Fruticultura, Jaboticabal, v. 25, n. 3, p. 440-442, 2003.

HARTMANN, T. H.; KESTER, D. E.; DAVIES, F. T.; GENEVE, R. Plant propagation: principles and practices. 6. ed. New Jersey: Prentice Hall, 1997.

KERMODE, A. R. Regulatory mechanisms involved in the transition from seed development to germination. Critical Reviews in Plant Sciences, Boca Raton, v. 9, $\mathrm{n}$. 1, p. 155-195, 1998.

HONG, T. D.; ELLIS, R. M. Optimum air-dry seed storage enviroments for arábica cofee. Seed Science and Tecnology, Zürich, v. 20, n. 3, p. 547-560, 1992.

JARDIM DE FLORES. A aromática canela. 2009. Disponível em: <http://www.jardimdeflores.com.br/ floresefolhas/A20canela.htm.>. Acesso em: 14 maio 2010.

MAGUIRE, J. D. Speed of germination-aid selection and evalution for seedling emergence and vigor. Crop Science, Madison, EUA, v. 2, n. 1, p. 176-177, 1962.

MARTINS, C. C.; NAKAGAWA, J.; BOVI, M. L. A. Tolerância à dessecação de sementes de palmitovermelho (Euterpe espiritosantensis Fernandes), Revista Brasileira Botânico, São Paulo, v. 22, n. 3, p. 391-396, 1999.

NASCIMENTO, W. M. O.; NOVEMBRE, A. L. C.; CICERO, S. M. Conseqüências fisiológicas da dessecação em sementes de açaí (Euterpe oleracea Mart.), Revista Brasileira de Sementes, Londrina, v. 29, n. 2, p. 38-43, 2007. 
ROBERTS, E. H. Predicting the storage life of seeds. Seed Science and Technology, London, v. 1, n. 1, p. 499514, 1973.

SALOMÃO, A. N.; FUJICHIMA, A. G. Respostas de sementes de Tabebuia aurea (Silva Manso) Benth e Hook. F. ex S. Moore (Bignoniaceae) à dessecação e ao congelamento em temperatura sub zero. Brasília: Embrapa/Cenargen, 2002. (Comunicado técnico, n. 76).
WALTERS, C. Levels of recalcitrance in seeds. Revista Brasileira de Fisiologia Vegetal, Campinas, v. 12, n. 1, p. 7-21, 2000. 
